Presentación del monográfico: "Poder municipal y regional en América: metodología, fuentes, archivos y experiencias comunes en su análisis"

Carlos Moreno Amador

Universidad de Sevilla (España)

José Luis Caño Ortigosa

Universidad de Cádiz (España) 



\title{
Presentación del monográfico: "Poder municipal y regional en América: metodología, fuentes, archivos y experiencias comunes en su análisis"
}

\section{Presentation of the monograph: "Municipal and regional power in America: methodology, sources, archives and common experiences in its analysis"}

\author{
Carlos Moreno Amador \\ Universidad de Sevilla (España) \\ carlosmoreno@us.es \\ José Luis Caño Ortigosa \\ Universidad de Cádiz (España) \\ joseluis.ortigosa@uca.es
}

Fecha de recepción: 4 de diciembre de 2020

Fecha de aceptación: 28 de febrero de 2021

\section{Resumen}

En este número de Revista de Humanidades se abordan de forma monográfica diferentes aspectos relacionados con el ejercicio del poder municipal y regional en América (metodología, fuentes, archivos y experiencias comunes en su análisis).

Palabras clave: Poder municipal; Poder regional; Metodología de investigación histórica; Fuentes de investigación histórica; Hispanoamérica

\begin{abstract}
In this issue of Revista de Humanidades, different aspects related to the exercise of municipal and regional power in America are addressed in a monographic manner (methodology, sources, files and common experiences in their analysis).
\end{abstract}

Keywords: Municipal power; Regional power; Historical research methodology; Historical research sources; Hispano-America 
El interés del estudio por los poderes locales y regionales para la investigación histórica americanista viene siendo evidenciado desde hace décadas. Y ello no solo por los especialistas en instituciones coloniales, sino también por los interesados en las economías, en las sociedades y en los rasgos culturales que se fueron configurando en cada lugar como resultado de la adaptación de las leyes imperiales a las idiosincrasias y condicionantes particulares por parte de las autoridades municipales, provinciales y regionales.

Las nuevas temáticas de investigación aparecidas en los últimos años, englobadas por algunos bajo el nombre de estudios postcoloniales, han visto en el ejercicio del poder municipal una importante fuente de información. Y es que, esos poderes no dejaban de ser los protagonistas de las políticas y de la justicia aplicadas de manera más cercana y directa a todo tipo de individuos, grupos humanos y sociales, a la par que sus élites dirigentes se constituían como un reflejo concreto y diferenciado de sus sociedades particulares. Un reflejo que, a su vez, se evidenciaba en sus decisiones concernientes a aspectos como el urbanismo, las infraestructuras, la educación, la salud pública, la relación con el medio ambiente, la respuesta ante catástrofes naturales, la apuesta por sectores económicos e, incluso, el tipo y nivel de engarce deseado dentro del imperio en coyunturas concretas.

Todo ello ha derivado también en un mejor y mucho más variado uso de las fuentes disponibles, así como en la utilización de más tipos documentales generados por estos poderes y en la multiplicación de métodos y preguntas de investigación. La incorporación a este tipo de trabajos de fuentes locales y regionales de carácter notarial, judicial, hacendística, particular, militar, literaria, audiovisual, oral, etc., proporcionan información valiosa para reconstruir la Historia en una amplia suerte de materias, que van desde la producción artística a las formas de relación familiar, a la organización social e institucional -no sólo en lo relativo a las élites, sino también de las minorías y grupos subalternos-, a la modificación del medio geográfico y la utilización de los recursos naturales o, incluso, de los sistemas de valores comunitarios, entre otras muchas cuestiones.

Este dossier pretende dar cabida, en mayor o menor medida, a algunos de esos temas, abordándolos desde una perspectiva local y regional e incorporando el interés por los métodos de investigación aplicados, el uso de los diferentes tipos de fuentes, la custodia y conservación de ellas y los nuevos retos que afronta la disciplina. En ese sentido, se observan varias temáticas que articulan el hilo argumental del mismo, centradas en el estudio de la sociedad, la economía y la municipalidad; el análisis de instituciones y su papel en el ámbito local y provincial; los servicios e infraestructuras propias del mundo local y regional; o el examen de algunas de las principales fuentes de estudio relacionadas con dicha realidad. Más allá de la diversidad temática, el denominador común de todos los trabajos lo marca, precisamente, el cotejo y uso de las fuentes, métodos y temas de estudio que giran alrededor de localidades y regiones concretas -entendidas éstas 
en un sentido amplio y variado de definición de las mismas- como herramienta para la reconstrucción de la Historia de América.

El objetivo último de esta propuesta ha sido el de reunir a investigadores que trabajan el mismo tipo de unidades de estudio y que, sobre materias, lugares y momentos diversos, encuentran problemas metodológicos similares, utilizan herramientas compartibles y aspiran a encontrar soluciones comunes.

El primero de los trabajos del dossier, firmado por el investigador José Luis Caño Ortigosa (Universidad de Cádiz), tiene por título Economía municipal en el Guanajuato de las reformas borbónicas. Instantánea de un quinquenio (1788-1792). En el mismo, el autor avanza en el todavía escaso conocimiento de las haciendas municipales de las poblaciones de la América colonial, utilizando como muestra los ingresos y gastos del ayuntamiento de Guanajuato en un lustro de fines del siglo XVIII, con el objetivo de realizar un acercamiento a una mejor comprensión de la capacidad recaudatoria de los municipios y el destino que se les daba a esas cantidades obtenidas. Asimismo, ofrece una panorámica sobre los cambios que se fueron produciendo en las rentas de los municipios coloniales con la implantación de las nuevas normas derivadas de las reformas borbónicas.

En el ámbito de la historia social se presenta el artículo de la profesora Ana Sofía Solano Acuña (Universidad Nacional-Costa Rica), Voces, imágenes y escritos que rememoran el pasado: metodología para la recuperación de la memoria histórica indígena del occidente de Panamá. Su propuesta pretende compartir la experiencia metodológica realizada alrededor de la historia de resistencia del pueblo indígena guaymí entre 1880 a 1925, como forma de recuperación de parte de la memoria histórica del occidente de Panamá. Como se expone a lo largo de su trabajo, la reconstrucción de hechos, sujetos, ideas y procesos a través de una polifonía de voces, visiones y fuentes, permiten al lector acercarse a este sector olvidado y desdibujado desde la historia nacional panameña y costarricense. Para la autora, el periodo temporal en el que se centra la investigación resulta de gran importancia, pues propuso los cimientos para la relación que estos sectores poblacionales tendrían posteriormente con el Estado, de ambos países, durante todo el siglo veinte.

Con respecto al análisis del papel que desarrollaron las instituciones en el contexto municipal y provincial, son varios los trabajos que recoge este dossier. El primero de ellos, del catedrático emérito Julián B. Ruiz Rivera (Universidad de Sevilla), lleva por título El cabildo de Cartagena de Indias, una pandilla dominada por Vicente de Peñalosa (1675-1680). Se trata de un estudio de caso en el cabildo de Cartagena de Indias, donde se observan las vicisitudes que podían llegar a acontecer en estos organismos: la pugna entre el regidor Vicente de Peñalosa y el teniente general Domingo de la Rocha, el primero sin estudios y el segundo licenciado en Cánones. Peñalosa, que atesoraba antepasados con muchos servicios a la Corona y en las conquistas, quiso dar el salto a Cartagena como escribano, aun frente a las negativas opiniones de los vecinos: inquieto, revoltoso, pleitista y sedicioso. Pese 
a contar con dos cédulas reales que lo avalaban, el cabildo recurrió al Consejo de Indias evitando que alcanzase dicho puesto. Sin embargo, gracias a sus amistades logró ser elegido regidor de Cartagena, donde consiguió dominar el cabildo contra la opinión del teniente general. En su enfrentamiento con de la Rocha logró que este último, ascendido ya a oidor de Santa Fe, fuera condenado en una causa judicial. De nada sirvieron los inmejorables informes sobre de la Rocha frente a las influencias cortesanas de Peñalosa.

En la línea de estudio de los cabildos el también catedrático Miguel Molina Martínez (Universidad de Granada), aporta un interesante trabajo titulado Venalidad, práctica cotidiana y ritual. A propósito del empleo de depositario general en el cabildo de Quito, 1777-1783. Para el autor, la investigación sobre los cabildos indianos viene demostrando en las últimas décadas una inusitada capacidad para profundizar e innovar en el análisis y caracterización del poder municipal. Igualmente, considera que la realidad demuestra que, más allá de planteamientos comunes o generalistas, el estudio de esta institución está abierto a la singularidad local que determina el propio territorio y la configuración socioeconómica en los que se desenvuelve.

En ese sentido, el artículo propone una mirada hacia las interconexiones que relacionan la venalidad con el ritual asociado a la misma. La propuesta se acerca al cabildo a través de tres conceptos (venalidad, práctica cotidiana y ritual) con el fin de explorar una faceta de la institución no demasiado transitada y que pone en relación la venta de oficios con los espacios, los símbolos y los ceremoniales que acompañan a su desarrollo. El uso de la costumbre, la plaza pública, los pregones, la puja, la toma de posesión y el juramento, entre otros aspectos, configuran un escenario cotidiano que transforma al comprador del oficio en sujeto activo de jurisdicción real. En su investigación, Molina presta especial atención al proceso de la puja por el empleo, utilizando para su análisis expedientes de remate de oficios y actas de confirmación real.

Por su parte, la investigadora María Dolores Palomo Infante (CIESAS Sureste, México) nos presenta el trabajo Acercamiento metodológico al estudio del poder local: los ayuntamientos de Chiapas (México). Siglo XIX. La autora plantea entre sus reflexiones el reto que supone acercarse al conocimiento de esta institución en regiones en las que desafortunadamente las fuentes de información son escasas, porque los archivos han desaparecido o son difíciles de consultar -como es el ejemplo de Chiapas, México-, motivo que justifica, entre otras cosas, una ausencia notable de estudios sobre el poder local. El estudio se centra en los ayuntamientos de pueblos indígenas ladinizados, aquellos en los que la mayor parte de su población era indígena, pero tenían un número importante de vecinos ladinos. Este factor, junto con la trayectoria histórica y el contexto del momento, caracterizó el desarrollo del gobierno local en la región. El artículo señala algunas preguntas, temas pendientes y perspectivas de análisis de esta institución, teniendo en cuenta, 
además, que la información documental disponible es escasa. Igualmente, analiza algunos aspectos que caracterizaron los procesos históricos de Chiapas relacionados con esta institución: carácter étnico de la población, consecuencias de la aplicación de los postulados de la constitución de Cádiz -igualdad jurídica, ciudadanía-, formas de representación o el carácter de los ayuntamientos, entre otras.

También en la línea de estudio del papel desempeñado por las instituciones de carácter municipal se encuadra el trabajo de Marisol Aguilar Echeverría (Universidad de las Fuerzas Armadas, ESPE) y Cristian Espinel López (Universidad de Granada) sobre El papel desempeñado por los concejos municipales de la República del Ecuador en el reclutamiento de soldados (18301860). Su trabajo pretende concatenar las funciones asignadas a los municipios por parte de la función ejecutiva y legislativa de la república del Ecuador para la dotación de individuos que fueron destinados a reforzar la tropa del Ejército Permanente y, así, cumplir objetivos específicos determinados por el gobierno de turno. El ensayo se basa en el resultado de la indagación de documentos cuya información dan cuenta del proceso de recluta por parte de los consejos municipales en base a normativa específica. Esta investigación contempla, además, el rol desempeñado por los cuerpos de milicia en las ciudades como refuerzo a la labor cotidiana de la guardia policial. En ese sentido, los autores consideran que la institución municipal durante los primeros años de Ecuador como república tuvo una participación decisiva en el proceso de alistamiento de soldados.

Con respecto a los servicios e infraestructuras propias del mundo local y regional, el dossier incluye el trabajo de Eduardo Azorín García (Universidad Pablo de Olavide), titulado Alumbrado, limpieza y recogida de basuras en La Habana de Ezpeleta: bandos y reglamento (1786-1787). En su investigación, el autor hace referencia a la llegada de la ciencia de la policía y los preceptos ilustrados sobre urbanismo a la ciudad de La Habana en la segunda mitad del siglo XVIII, en consonancia con el resto de la monarquía hispánica. Esta coyuntura dejó como testimonio una serie de documentos normativos de carácter ejecutivo que emanaban directamente del poder local y regulaban prácticas y aspectos de orden público en el entorno urbano para un mayor control de la población. Desde esta perspectiva, Azorín centra su interés en el análisis de tres bandos y un reglamento que dictaron la implementación del alumbrado público y de un sistema de limpieza y recogida de basuras en La Habana durante el mandato del gobernador José Manuel de Ezpeleta a finales del siglo XVIII.

En lo relativo al análisis de las fuentes de estudio relacionadas con el ámbito provincial y local, el dossier recoge dos investigaciones ciertamente pertinentes. La primera, a cargo de Carlos Moreno Amador (Universidad de Sevilla), que lleva por título $E l$ poder regional a examen: irregularidades y singularidades en los juicios de residencia de Tabasco (1666-1707), centra su interés en analizar algunas de las irregularidades y peculiaridades más importantes que los juicios de 
residencia indianos mantuvieron a lo largo de todo el periodo colonial, como fueron las composiciones, las recusaciones, el acompañamiento de testigos, la actuación desempeñada por el escribano de residencia y la carestía de papel sellado que debía utilizarse en dichos procesos, toda vez que llegaron a condicionar el desarrollo y el resultado de los mismos en no pocas ocasiones. Para tal fin, utiliza el contexto que ofrece la región de Tabasco, considerando la posibilidad de disponer de una serie de juicios de residencia continuados en el tiempo, que abarcan el periodo 1666-1707.

Por último, Ana de Zaballa Beascoechea (Universidad del País Vasco, UPV/EHU), en su artículo La visita pastoral como fuente privilegiada para la historia local. Un ejemplo de la Nueva España del siglo XVII, realiza un magnífico planteamiento sobre la riqueza de la visita pastoral del obispo a su diócesis como fuente para conocer la vida y la sociedad, tanto de localidades concretas como de regiones más amplias. La autora recuerda, también, que la visita pastoral era desde el concilio de Trento una obligación anual del obispo, aunque defiende que en Indias la realidad fue que pocos prelados lograron hacer la visita completa a su territorio debido a la amplitud territorial de estos obispados. Sin embargo, la posibilidad de disponer de varias visitas en el ámbito de la Nueva España permite conocer aspectos a nivel local, tanto de su organización social como territorial, su actividad agropecuaria o artesanal; siempre dependiendo de los intereses del obispo y, por tanto, del contenido del Diario de visita. En ese sentido, en dicha investigación se plantea igualmente el provecho de contrastar dicha documentación con otras fuentes eclesiásticas que la complementan, como son los libros de cordilleras o los procesos de los tribunales eclesiásticos.

Al hilo de todo lo anterior, resulta evidente que el interés de este dossier radica, fundamentalmente, en aportar algo más de conocimiento a los estudios que sobre la temática se vienen desarrollando en los últimos tiempos, además de ofrecer la posibilidad de abrir nuevas líneas de investigación a los especialistas de la materia gracias a los aportes realizados por los autores que en él participan. 